University of Nebraska - Lincoln

DigitalCommons@University of Nebraska - Lincoln

Sociology Department, Faculty Publications

Sociology, Department of

2011

\title{
The Effect of Poor Parenting on Male and Female Dating Violence Perpetration and Victimization
}

\author{
Kimberly A. Tyler \\ University of Nebraska-Lincoln, kim@ktresearch.net \\ Douglas A. Brownridge \\ University of Manitoba, Douglas_Brownridge@umanitoba.ca \\ Lisa A. Melander \\ Kansas State University, Imeland@ksu.edu
}

Follow this and additional works at: https://digitalcommons.unl.edu/sociologyfacpub

Part of the Sociology Commons

Tyler, Kimberly A.; Brownridge, Douglas A.; and Melander, Lisa A., "The Effect of Poor Parenting on Male and Female Dating Violence Perpetration and Victimization" (2011). Sociology Department, Faculty Publications. 153.

https://digitalcommons.unl.edu/sociologyfacpub/153

This Article is brought to you for free and open access by the Sociology, Department of at DigitalCommons@University of Nebraska - Lincoln. It has been accepted for inclusion in Sociology Department, Faculty Publications by an authorized administrator of DigitalCommons@University of Nebraska - Lincoln. 


\title{
The Effect of Poor Parenting on Male and Female Dating Violence Perpetration and Victimization
}

\author{
Kimberly A. Tyler, PhD \\ University of Nebraska-Lincoln \\ Douglas A. Brownridge, PhD \\ University of Manitoba, Canada \\ Lisa A. Melander, PhD \\ Kansas State University
}

\begin{abstract}
This study examines the effects of poor parenting on dating violence perpetration and victimization among approximately 900 males and females from the National Longitudinal Survey of Adolescent Health (Add Health). Results revealed that more physical abuse and low parental warmth were linked to greater substance use and higher rates of delinquency. In addition, low parental warmth, more neglect, and greater delinquency had positive direct effects on dating violence perpetration, whereas more physical abuse, low parental warmth, and increased delinquency were all positively associated with dating violence victimization. Finally, delinquency mediated the link between low parental warmth and dating violence perpetration and victimization. The results provide some support for both social learning theory and an antisocial orientation perspective.
\end{abstract}

Keywords: child maltreatment, poor parenting, dating violence, perpetration, victimization

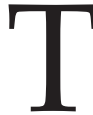

he victimization of intimate partners is one of the most prevalent forms of violence in contemporary society (Wolfe \& Feiring, 2000). In the United States alone, almost 1.5 million women and approximately 835,000 men are physically assaulted and/or raped by an intimate partner each year (Tjaden \& Thoennes, 2000b). Violence is also widespread in dating relationships, which typically includes high school or middle school adolescents or unmarried, noncohabiting college students (Barnett, Miller-Perrin, $\&$ Perrin, 2005). For example, Straus (2004) found that among 33 university samples in 17 countries, the prevalence of physical assault perpetration among dating couples ranged from $17 \%$ to $45 \%$. The effects of these experiences may last much longer than the initial violent experience and may result in poor mental health outcomes, such as depression and low self-esteem (Anderson, 2002; DeMaris \& Kaukinen, 2005).

Various theoretical perspectives have been used to understand how negative childhood and adolescent experiences are linked to young adult relationship violence. Social learning theory (Bandura, 1977), which posits that childhood exposure to violence in the 
family of origin will lead to an increased likelihood of perpetrating and experiencing violence in intimate relationships, provides theoretical rationale for the intergenerational transmission of violence explanation (Stith et al., 2000). The intergenerational transmission framework, however, has been met with mixed support as most child abuse victims do not engage in violence within their intimate relationships (Kaufman \& Zigler, 1987; Mihalic \& Elliott, 1997; Spatz Widom, 1989). Some researchers have also examined an antisocial orientation perspective (Gordon Simons, Burt, \& Simons, 2008), which suggests that children exposed to poor parenting such as abuse and low warmth and support, are at greater risk for dating violence through antisocial behaviors such as delinquency and substance use. In other words, a general pattern of antisocial behavior is passed from parents to their children. Research using this perspective has found support for victimization (Brownridge, 2006) and perpetration (Fang \& Corso, 2007; Gordon Simons et al., 2008; Simons, Lin, \& Gordon, 1998).

Previous dating violence research has several limitations regarding sample composition (e.g., female, male, or college only), types of violence included, and analytic designs (i.e., all variables measured at the same wave). Additionally, other studies on intimate violence among young adults incorporate various relationship types, such as dating, cohabiting, and married individuals, even though these groups are quite different in terms of investment, involvement, and rates of violence (Barnett et al., 2005; Stets \& Straus, 1990). In an effort to avoid the limitations of previous studies, this study examined the effect of poor parenting and child maltreatment on combined measures of physical, psychological, and sexual dating violence perpetration and victimization through antisocial behavior among a sample of males and females in the general population.

\section{Potential Modes of Intergenerational Transmission}

This study proposes both a social learning approach and an antisocial orientation perspective to understand the process that links poor parenting to dating violence perpetration and victimization. According to social learning theory, violence toward others is a learned behavior (Bandura, 1977). Children who grow up in violent homes learn the techniques of being violent, as well as the justifications for this behavior (e.g., "It's for his own good"; Gelles, 1997). Consequently, childhood victims of violence not only learn how to be perpetrators, but they also may learn the social scripts necessary for becoming victims of violence as they have internalized rationalizations for interpersonal violence. There has been empirical support for these findings because experiencing physical abuse, sexual abuse, and/or neglect in childhood has been directly linked to victimization (Brownridge, 2006), perpetration (Herrenkohl et al., 2004; Swinford, DeMaris, Cernkovich, \& Giordano, 2000), or both (Gover, Kaukinen, \& Fox, 2008; Whitfield, Anda, Dube, \& Felitti, 2003; Wolfe, Wekerle, Scott, Straatman, \& Grasley, 2004) within intimate relationships.

Another mode of intergenerational transmission, which has been labeled as the antisocial orientation or criminological perspective (Gordon Simons et al., 1998; Simons et al., 2008), suggests that children who are exposed to poor parenting, such as abuse and low levels of support, are at greater risk for dating violence through delinquent behavior and substance use. In other words, a general pattern of antisocial behavior is passed from parents to their children, and because the children's antisocial tendencies persist throughout the life span, this affects the probability that they will engage in dating violence. Individuals who experience child maltreatment may also experience lower levels of parental warmth, which is linked with dating violence. For example, Brendgen, Vitaro, Tremblay, 
and Lavoie (2001) found that low maternal warmth was associated with dating violence perpetration among a longitudinal sample of high school boys. In addition to predicting dating violence perpetration, Brownridge (2006) found that characteristics related to antisocial tendencies contributed to an increased likelihood of being a victim of assault.

According to the antisocial orientation perspective, it is important to consider behaviors, such as substance use and delinquency, as mediators when examining the association between child maltreatment and dating violence. Delinquency has been found to mediate the relationship between child abuse and partner violence perpetration (Swinford et al., 2000) as well as between poor parenting and perpetration (Simons et al., 1998). Although they did not find support for mediation, Lavoie et al. (2002) found that harsh discipline and delinquency were both directly associated with perpetrating dating violence. As such, there is mixed support for delinquency as a potential mediator of partner violence.

Based on the preceding literature review and theories, we propose the following hypotheses. According to social learning theory, we hypothesized that child maltreatment (i.e., physical abuse, sexual abuse, and neglect) and low levels of parental warmth would be directly associated with dating violence perpetration and victimization. Second, according to an antisocial orientation perspective, we hypothesized that child maltreatment and lower levels of parental warmth would be positively associated with antisocial behavior, including substance use and delinquency. Third, we hypothesized that child maltreatment and lower levels of parental warmth would be indirectly and positively associated with dating violence perpetration and victimization through antisocial behaviors. Fourth, we expected that both substance use and delinquency would be positively linked with dating violence perpetration and victimization. The main difference between these two perspectives is that social learning theory states that violence is learned and thus will have a direct effect on outcomes, whereas the antisocial orientation perspective posits that the effect of negative childhood experiences on dating violence is indirect through antisocial behaviors.

\section{Methods}

This study uses the National Longitudinal Study of Adolescent Health (Add Health), which is a nationally representative data set of adolescents in grades 7 through 12 (Harris et al., 2009), to examine the effect of poor parenting and child maltreatment on a combined measure of physical, psychological, and sexual dating violence. The Add Health survey, which explores the causes of health-related behaviors and their outcomes in young adulthood, was initiated in 1994 under a grant from the National Institute of Child Health and Human Development. This study makes use of Waves 1 through 3 (Harris, 2008).

A sample of 80 high school and 52 middle school male and female participants from the Northeastern, Midwestern, Southern, and Western regions of the United States were selected with an unequal probability of selection as a stratified random sample. Interviewers began contacting adolescents from eligible schools and their families between 1994 and 1995 during the first Wave of data collection (Harris et al., 2009). Respondents completed in-school questionnaires and then were interviewed at home by trained interviewers. Wave 2 data collection via in-home interviews began in April 1996 and ended in August 1996 and followed the same mode of questioning as in Wave 1. Data collection for Wave 3 began in July 2001 and concluded in April 2002 (Harris et al., 2009). 


\section{Sample Characteristics}

Because we were interested in only retaining individuals who were currently in a dating relationship, we used five criteria for sample selection: (a) heterosexual relationship, (b) current relationship, (c) romantic relationship, (d) exclusive dating relationship, and (e) no cohabitation history. This subsample included 558 females (54.4\%) and 467 males (45.6\%). The respondents were in grades 7 through 12 at Wave 1 with a median grade of 9. Almost one-half of the sample was White $(49.8 \%)$; slightly more than half were Black $(24 \%)$, Hispanic $(11.5 \%)$, and categorized as Other $(14.7 \%)$. At Wave 3, approximately $18 \%$ reported perpetrating dating violence against a current partner, whereas $17 \%$ indicated they had been a victim of this form of violence. Respondents ranged in age from 18 to 26 years at Wave 3 .

\section{Measures}

\section{Demographic Controls}

The demographic control variables were all measured during Wave 1. Gender was coded $0=$ male and $1=$ female. The respondent's grade was measured at Wave 1 and ranges from 7th grade to 12th grade. Race included four dichotomous variables: White non-Hispanic, Black non-Hispanic, Other non-Hispanic, and Hispanic of any race. White youth are used as the reference group.

\section{Independent Variables}

The child maltreatment variables, measured only in the Wave 3 interview, were modified versions of questions administered in previous surveys such as the Revised Conflict Tactics Scale (CTS2; Straus, Hamby, Boney-McCoy, \& Sugarman, 1996). The response categories for each child maltreatment variable (i.e., physical abuse, neglect, and sexual abuse) included $0=$ this has never happened, $1=$ once, $2=$ twice, $3=3$ to 5 times, $4=6$ to 10 times, and $5=$ more than 10 times. Physical abuse was measured using the following item: "How often had your parents or other adult caregivers slapped, hit, or kicked you?" A square root transformation was performed on this variable because of skewness. The range for the physical abuse item was 0 to $2.24(M=.39, S D=.71)$. Neglect was comprised of two items: "By the time you started sixth grade, how often had your parents or other adult caregivers left you home alone when an adult should have been with you?" and "How often had your parents or other adult caregivers not taken care of your basic needs, such as keeping you clean or providing food or clothing?" $(r=.17)$. The two-neglect items were summed with a higher score indicating more neglect and a square root transformation was performed because of skewness. The range for the neglect scale was $0-3.16(M=.60, S D=$ .85). Sexual abuse included the following question: "How often had one of your parents or other adult caregivers touched you in a sexual way, forced you to touch him or her in a sexual way, or forced you to have sexual relations?" This variable was dichotomized because of skewness $(0=$ this has never happened, $1=$ this happened at least once).

Lack of parental warmth was measured at Wave 1 and included six items regarding the respondent's relationship to his or her residential mother and residential father. These items included the following: (a) Most of the time, your mother/father is warm and loving toward you; (b) You are satisfied with the way your mother/father and you com- 
municate with each other; and (c) Overall, you are satisfied with your relationship with your mother $/$ father. Response categories ranged from $1=$ strongly agree to $5=$ strongly disagree. The mother and father responses to each of the preceding items were averaged and summed such that a higher score indicated lower levels of parental warmth $(M=2.24, S D$ $=2.13$ ). Cronbach's $\alpha$ was .86 .

Substance use was measured at Wave 2 using five items that asked respondents about their substance use since the Wave 1 interview. Respondents were asked if they had consumed the following substances: (a) beer, wine, or liquor; (b) marijuana; (c) cocaine; (d) inhalants; and (e) other illegal drugs (e.g., LSD, PCP, ecstasy). Response categories included $0=n o$ and $1=$ yes. A count variable was created that ranged from 0 to 3 .

Delinquency was measured at Wave 2 and included 11 items, which asked respondents, for example, how often they damaged property, stole a car, shoplifted, or sold drugs within the past 12 months. Response categories ranged from $0=$ never to $3=5$ or more times. The individual items were dichotomized because of skewness $(0=$ never, $1=$ at least once) and then summed. Because this summed scale was still skewed, the variable was collapsed and ranged from $0=$ never/none to $5=$ five or more types of delinquent acts $(M$ $=1.17)$. Cronbach's $\alpha$ was .75 .

\section{Dependent Variables}

Dating violence perpetration was measured at Wave 3 using three items that asked respondents about their violent behaviors toward a dating partner during the past year, including how often they (a) threatened, pushed or shoved, or threw something at a partner; (b) slapped, hit, or kicked a partner; and (c) forced their partner into sexual activities. Response categories for both perpetration and victimization included $0=$ never, $1=$ once, $2=$ twice, $3=3$ to 5 times, $4=6$ to 10 times, $5=11$ to 20 times, $6=$ more than 20 times, and $7=$ this has not happened in the past year but did happen before then. The seventh category (i.e., violence occurred prior to this year) was coded to 0 (never) because we were only interested in partner violence that occurred during the past year. Because of skewness, these three items were dichotomized $(0=$ never, $1=$ at least once $)$ and then summed. The final item was dichotomized because of skewness such that $0=$ this has never happened and $1=i t$ has happened at least once during the past year.

Dating violence victimization was measured at Wave 3 using three items that asked respondents about their partner's violent behaviors toward them during the past year, including how often their partner (a) threatened, pushed or shoved, or threw something at them; (b) slapped, hit, or kicked them; and (c) forced them into sexual activities. Because of skewness, these items were dichotomized $(0=$ never, $1=$ at least once $)$ and then summed. The final item was dichotomized because of skewness such that $0=$ this has never happened and $1=$ it has happened at least once during the past year.

\section{Results}

To explore the effects of maltreatment and poor parenting on dating violence perpetration and victimization, we estimated two fully recursive path models using the weighted least squares procedure in Mplus 5 (Muthén \& Muthén, 1998-2007). These two models take into account both the direct effects of maltreatment and poor parenting on dating violence perpetration and victimization as well as their indirect effects through substance 


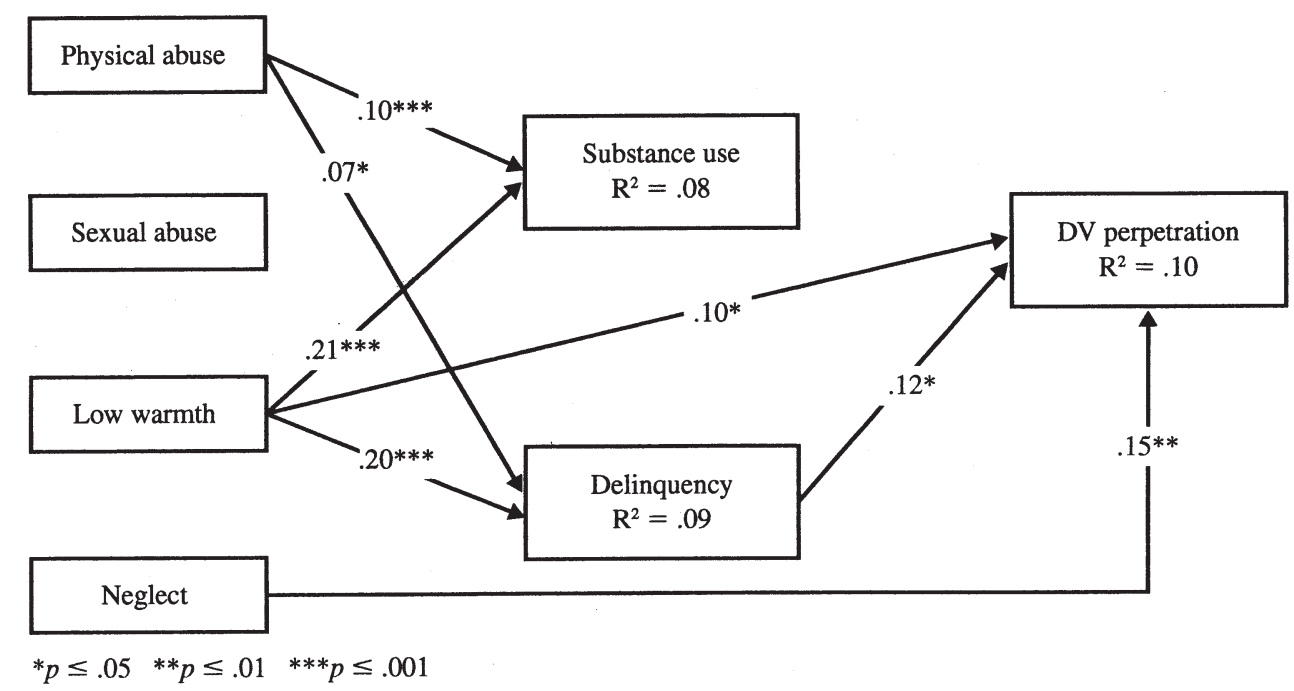

Figure 1. Path model for predictors of dating violence perpetration (only significant paths are shown).

use and delinquency (see Figures 1 and 2). For interpretation purposes, the standardized path coefficients ((3) reported in the subsequent texts represent the effect of a given predictor variable on the dependent variable after accounting for the remaining relationships in the model.

\section{Dating Violence Perpetration}

Results for dating violence perpetration in Figure 1 (standardized coefficients are shown) revealed that low parental warmth was positively associated with both substance use $(\beta=.21)$ and delinquency $(\beta=.20)$. Thus, those who experienced lower levels of parental warmth were significantly more likely to report higher levels of substance use and greater levels of delinquency compared to those with higher parental warmth. Additionally, young people who experienced more physical abuse reported greater substance use $(\beta=.10)$ and delinquent activities $(\beta=.07)$. Those who reported higher levels of neglect were more likely to perpetrate dating violence $(\beta=.15)$, as were those who experienced low parental warmth $(\beta=.10)$. Finally, youth with higher levels of delinquency were significantly more likely to perpetrate dating violence $(\beta=.12)$. These variables explained $10 \%$ of the variance in dating violence perpetration.

\section{Dating Violence Victimization}

Results for dating violence victimization appear in Figure 2 (standardized coefficients are shown). Similar to perpetration, low parental warmth was positively associated with both substance use $(\beta=.21)$ and delinquency $(\beta=.20)$, whereas physical abuse had positive effects on substance use $(\beta=.10)$ and delinquency $(\beta=.07)$. In addition, both low parental warmth and physical abuse had significant direct effects on dating violence victimization $(\beta=.14$ and $\beta=.15$, respectively). Finally, youth with higher levels of delinquency were significantly more likely to have been a victim of dating violence $(\beta=.16)$. These variables explained $12 \%$ of the variance in dating violence victimization. 


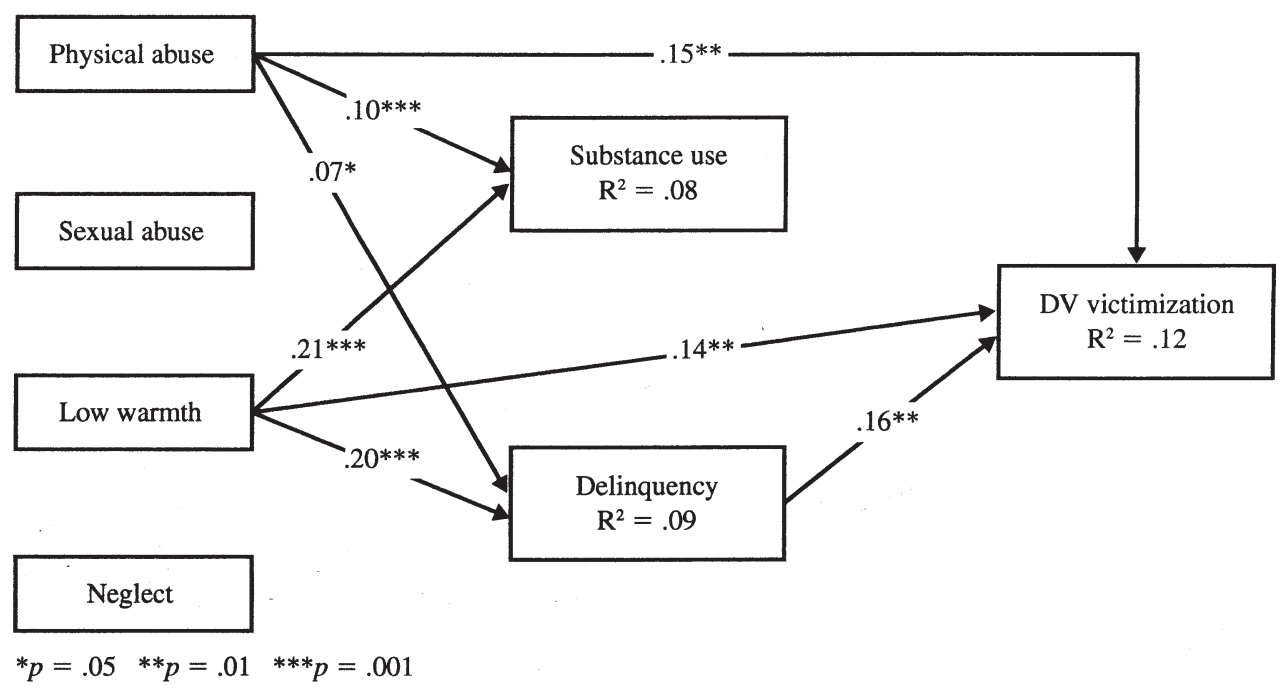

Figure 2. Path model for predictors of dating violence victimization (only significant paths are shown).

\section{Indirect Effects}

Table 1, which shows the direct, indirect, and total effects for the full model on dating violence perpetration at Wave 3, revealed that one of the demographic variables had a significant direct effect (see top half of Table 1). Females were significantly more likely to report having perpetrated dating violence compared to males $(\beta=.18)$. One demographic variable was significant in the dating violence victimization model: Black youths were significantly more likely to be victims of dating violence compared to White youths (see bottom half of Table 1).

In terms of total indirect effects on dating violence perpetration (see top half of Table 1), one demographic variable (gender) was significant. In addition to the positive direct effect, gender also had a significant indirect effect on dating violence perpetration through delinquency. Specifically, males had significantly higher levels of participation in delinquent activities (results not shown) which, in turn, was positively associated with dating violence perpetration. As such, males with higher rates of delinquency were more likely to perpetrate partner violence.

In terms of dating violence victimization (see bottom half of Table 1), two demographic variables (gender and grade) had significant indirect effects. Males had significantly higher levels of delinquent behavior (results not shown), which, in turn, was positively associated with dating violence victimization. In other words, males who participated in more delinquent activities were more likely to be victims of dating violence. Additionally, respondents in lower grades had significantly higher levels of delinquency (results not shown), which, in turn, was positively correlated with dating violence victimization.

\section{Discussion}

The purpose of this study was to examine the effects of poor parenting and child maltreatment on dating violence perpetration and victimization through delinquency and 
Table 1. Full Model Results (Standardized)

Dating Violence Perpetration

\begin{tabular}{|c|c|c|c|c|c|c|}
\hline Variables & $\begin{array}{l}\text { Direct Effect } \\
\text { Estimate }\end{array}$ & SE & $\begin{array}{l}\text { Total Indirect } \\
\text { Effect Estimate }\end{array}$ & SE & $\begin{array}{l}\text { Total } \\
\text { Effect }\end{array}$ & SE \\
\hline \multicolumn{7}{|l|}{ Demographic controls } \\
\hline Female & $.181^{* * *}$ & .107 & $-.020^{*}$ & .020 & $.162^{* * *}$ & .106 \\
\hline Grade & -.038 & .032 & -.013 & .005 & -.051 & .032 \\
\hline Latino & .069 & .169 & -.006 & .020 & .063 & .168 \\
\hline Black & .090 & .125 & -.005 & .019 & .085 & .125 \\
\hline Other & .067 & .146 & -.007 & .017 & .060 & .147 \\
\hline \multicolumn{7}{|l|}{ Parenting constructs } \\
\hline Physical abuse & .076 & .072 & .007 & .009 & .083 & .071 \\
\hline Sexual abuse & -.004 & .258 & -.002 & .026 & -.006 & .263 \\
\hline Low parental warmth & $.102 *$ & .024 & .022 & .006 & $.124^{* *}$ & .023 \\
\hline Neglect & $.145^{* *}$ & .063 & .007 & .007 & $.152^{* *}$ & .063 \\
\hline \multicolumn{7}{|l|}{ Mediating constructs } \\
\hline Substance use & -.010 & .064 & & & & \\
\hline Delinquency & $.119^{*}$ & .039 & & & & \\
\hline
\end{tabular}

Dating Violence Victimization

Demographic controls

Female

Grade

Latino

Black

Other

$\begin{array}{cc}-.048 & .106 \\ -.069 & .033 \\ -.026 & .189 \\ .118^{*} & .125 \\ .073 & .149\end{array}$

$-.024^{*} \quad .021$

$-.018^{*} \quad .006$

$-.072$

$-.087$

$-.032$

$.115^{*}$

.066

\begin{tabular}{ll}
$-.006 \quad .024$ \\
\hline
\end{tabular}

$-.003 \quad .021$

$-.007 \quad .020$

.105

.033

.191

.124

.150

Parenting constructs

\begin{tabular}{lllllll} 
Physical abuse & $.145^{* *}$ & .072 & .006 & .011 & $.150^{* *}$ & .073 \\
Sexual abuse & .001 & .237 & -.002 & .034 & -.001 & .246 \\
Low parental warmth & $.136^{* *}$ & .025 & .023 & .006 & $.159^{* *}$ & .025 \\
Neglect & .091 & .062 & .010 & .008 & $.101^{*}$ & .063 \\
Mediating constructs & & & & & & \\
Substance use & -.047 & .063 & & & \\
Delinquency & $.161^{* *}$ & .037 & & & \\
\hline
\end{tabular}

${ }^{*} p \leq .05 ;{ }^{* *} p \leq .01 ; * * * p \leq .001$ 
substance use among a sample of males and females in the general population. Consistent with previous studies, we find that violence is prevalent in dating relationships in the form of both perpetration and victimization (Brownridge, 2006; Katz, Kuffel, \& Coblentz, 2002; Tjaden \& Thoennes, 2000b; Williams \& Frieze, 2005). In addition, we find that our prevalence rate for dating violence is consistent with what Straus (2004) found in his cross-cultural study of 33 universities.

We proposed both a social learning approach and an antisocial orientation and found some support for both frameworks. Physical abuse, neglect, and low parental warmth are directly associated with dating violence perpetration and/or victimization, which is consistent with a social learning theory interpretation. Our results are also consistent with those who find that maltreatment in childhood is directly linked to violence within intimate relationships (Brownridge, 2006; Gover et al., 2008; Herrenkohl et al., 2004). Those who experience violence in childhood may learn that violence can be an effective and normative response to conflict and are more likely to imitate these behaviors in their own relationships than individuals from nonviolent homes (Bandura, 1977; Gray \& Foshee, 1997; Stith et al., 2000). Because violence toward others is a learned behavior (Bandura, 1977), children who grow up in these homes may learn the techniques of being violent as well as the justifications for this behavior (Gelles, 1997). Consequently, victims of childhood violence learn how to be aggressive and also learn the social scripts necessary for becoming victims of violence as they have internalized rationalizations for interpersonal aggression.

In terms of dating violence perpetration, our results are also supportive of an antisocial orientation or criminological perspective. According to this perspective, antisocial behaviors, such as delinquency and substance use, are important mediators in understanding the association between child maltreatment, poor parenting, and dating violence. Our results indicate that those who experience lower levels of parental warmth are more likely to engage in antisocial behavior (i.e., delinquency and substance use), but only delinquency is, in turn, linked to dating violence perpetration. This is consistent with the previous work that finds support for the mediation effect of antisocial behaviors on dating violence perpetration (Simons et al., 1998). According to the antisocial orientation or criminological perspective (Gordon Simons et al., 1998; Simons et al., 2008), children exposed to poor parenting, including low parental warmth are at greater risk for being a perpetrator of dating violence through antisocial behaviors. This indicates that a general pattern of antisocial behavior is passed from parents to their children. That is, lacking warm and supportive ties with parents, youth may gravitate toward deviant peer groups, which reinforces antisocial behavior. Because antisocial behaviors may persist throughout the life span, this increases the likelihood that youth will engage in other forms of deviant behavior, including dating violence perpetration. A period of approximately 5 or 6 years separates Waves 2 and 3; consequently, the effect of antisocial behavior continues to impact the likelihood of perpetrating dating violence several years later. In sum, social learning theory emphasizes that violence is learned and thus will have a direct effect on outcomes, whereas the antisocial orientation perspective posits that this effect is indirect through deviant behaviors. Because there are both direct and indirect effects in our models, we find support for both theoretical perspectives.

Although neither perspective necessarily posits gender differences in violence perpetration, our results reveal a direct association between gender and dating violence perpetration. As such, females are more likely to report perpetrating dating violence. These results are consistent with some previous research using modified versions of the Conflict Tactics Scale items (Whitaker, Haileyesus, Swahn, \& Saltzman, 2007; Williams \& Frieze, 
2005) and may be attributed to the contention that women may be more willing to admit to using violence compared to males because men may be afraid of the negative stigma associated with victimizing a woman (Gover et al., 2008). Furthermore, these results may be caused by the items used for the dating violence measures as previous research has found that men may use more severe forms of violence (Capaldi et al., 2009), whereas indicators in this study tended to include milder forms.

In terms of dating violence victimization, we also find general support for both perspectives. We find that physical abuse and low parental warmth are both directly associated with dating violence victimization, which supports a social learning interpretation. Children who have poor relationships with their parents are more likely to learn maladaptive interaction patterns that result in the selection and creation of new environments that are congruent with past interaction styles (Caspi, Elder, \& Bern, 1987). As a result, young people who experience family abuse may expect this type of violence in future relationships because it is what they experienced during childhood. As such, they may learn the social scripts necessary for becoming victims and, thus, experience more dating violence.

In terms of an antisocial orientation perspective, adolescents who experience lower levels of parental warmth are more likely to participate in delinquent activities, which, in turn, are associated with being a victim of dating violence. Once again, it appears that a general pattern of antisocial behavior is passed from parents to their children. Those who perceive their relationship with their parents as being distant, unsatisfactory, and lacking communication (i.e., low parental warmth) may look elsewhere for companionship and thus may be drawn toward high-risk individuals, increasing their chances of being a victim within their dating relationships. Because much of the variance in perpetration and victimization was not explained, future studies should examine other theoretically informed variables such as interparental violence.

Some limitations should be noted with this study. First, respondents were asked to report on their partners' violence toward them, which may have resulted in some over or underreporting. Second, the data set included few separate indicators of violence and, thus, we were unable to leave the outcome variables continuous, perhaps limiting our ability to explain dating violence. Similarly, the data do not include information on the severity, duration, or intent of the perpetration. Third, although women reported victimizing their partner more often, the context and motivations behind the violent behavior are unknown; thus it is possible that much of their violence was in retaliation for violence directed at them or as a means of self-defense. Fourth, the measures of child maltreatment were retrospective because they were only administered during the Wave 3 interview. Thus, the current situation of some youth, such as their recent relationship with their caregivers, and their ability to recall with accuracy the occurrence of these incidents may have influenced their responses to these questions. Furthermore, limited indicators of physical abuse existed in the current data. Finally, respondents were only asked whether their parents or other caregivers sexually abused them, which does not account for sexual experiences perpetrated by other individuals.

Notwithstanding these concerns, our data also has several strengths, which allowed us to address many of the shortcomings in the literature. We used a data set of more than 900 males and females in the general population to examine both dating violence perpetration and victimization. Examining the relationship between gender and dating violence is important, given that findings in the literature are mixed with regard to the prevalence of victimization and perpetration among men and women (Foshee et al., 2009; 
Tjaden \& Thoennes, 2000a; Wekerle et al., 2009). Additionally, we focused specifically on dating violence, which is important given that relationship types (i.e., dating, cohabiting, and married individuals) are often combined and are quite different in terms of investment, involvement, and rates of violence (Brownridge, 2009; Stets \& Straus, 1990). Finally, our data allowed us to examine mediators that are important for understanding dating violence. The fact that our mediators were measured at least 5 years prior to our outcome variables and that they were related to physical abuse and low parental warmth reveals the persistent and detrimental effect that negative parenting can have on a child's future relationships.

\section{Implications}

At the policy level, these results have practical implications for service providers and researchers. Because dating violence perpetration and victimization was experienced by both females and males, this suggests that service providers need to be sensitive to the concerns and experiences of all victims, regardless of gender, to adequately treat and prevent this devastating social problem. Service providers must also address not only the early familial variables related to dating violence, including physical abuse and poor parenting, but also more proximal indicators including delinquent behavior and substance use. A broader approach to intervention may be necessary given that both proximal and distal events are precursors to dating violence. More research is needed with the general population samples, especially those that include youth. If we do not intervene early in their dating experiences, many of these young people may develop violent relationship patterns that persist throughout their lives and that involve relationship forms, such as cohabitation and marriage, which are even more difficult to dissolve than dating unions.

\section{References}

Anderson, K. L. (2002). Perpetrator or victim? Relationships between intimate partner violence and well-being. Journal of Marriage and Family, 64(4), 851-863.

Bandura, A. (1977). Social learning theory. Orrville, OH: Prentice Hall.

Barnett, O. W., Miller-Perrin, C. L., \& Perrin, R. D. (2005). Family violence across the life span: An introduction (2nd ed.). Thousand Oaks, CA: Sage Publications.

Brendgen, M., Vitaro, R., Tremblay, R. E., \& Lavoie, F. (2001). Reactive and proactive aggression: Predictions to physical violence in different contexts and moderating effects of parental monitoring and caregiving behavior. Journal of Abnormal Child Psychology, 29(4), 293-304.

Brownridge, D. A. (2006). Intergenerational transmission and dating violence victimization: Evidence from a sample of female university students in Manitoba. Canadian Journal of Community Mental Health, 25(1), 75-93.

Brownridge, D. A. (2009). Violence against women: Vulnerable populations. New York: Routledge.

Capaldi, D. M., Shortt, J. W., Kim, H. K., Wilson, J., Crosby, L., \& Tucci, S. (2009). Official incidents of domestic violence: Types, injury, and associations with nonofficial couple aggression. Violence and Victims, 24(4), 502-519.

Caspi, A., Elder, G. H., Jr., \& Bern, D. J. (1987). Moving against the world: Life-course patterns of explosive children. Developmental Psychology, 23(2), 308-313.

DeMaris, A., \& Kaukinen, C. (2005). Violent victimization and women's mental and physical 
health: Evidence from a national sample. Journal of Research in Crime and Delinquency, 42(4), 384-411.

Fang, X., \& Corso, P. S. (2007). Child maltreatment, youth violence, and intimate partner violence: Developmental relationships. American Journal of Preventive Medicine, 33(4), 281-290.

Foshee, V. A., Benefield, T., Suchindran, C., Ennett, S. T., Bauman, K. E., Karriker-Jaffe, K. J., et al. (2009). The development of four types of adolescent dating abuse and selected demographic correlates. Journal of Research on Adolescence, 19(3), 380-400.

Gelles, R. J. (1997). Intimate violence in families (3rd ed.). Thousand Oaks, CA: Sage Publications, Inc.

Gordon Simons, L., Burt, C. H., \& Simons, R. L. (2008). A test of explanations for the effect of harsh parenting on the perpetration of dating violence and sexual coercion among college males. Violence and Victims, 23(1), 66-82.

Gover, A. R., Kaukinen, C., \& Fox, K. A. (2008). The relationship between violence in the family of origin and dating violence among college students. Journal of Interpersonal Violence, 23(12), 1667-1693.

Gray, H. M., \& Foshee, V. (1997). Adolescent dating violence: Difference between one-sided and mutually violent profiles. Journal of Interpersonal Violence, 12(1), 126-141.

Harris, K. M. (2008). The national longitudinal study of adolescent health (Add Health), Waves I \& II, 1994-1996; Wave III, 2001-2002 [machine-readable data file and documentation]. Chapel Hill, NC: Carolina Population Center, University of North Carolina at Chapel Hill.

Harris, K. M., Halpern, C. T., Whitsel, E., Hussey, J., Tabor, J., Entzel, P., \& Udry, J. R. (2009). The national longitudinal study of adolescent health: Research design. Retrieved May 3, 2011 from http://www.cpc.unc.edu/projects/addhealth/design

Herrenkohl, T. I., Mason, W. A., Kosterman, R., Lengua, L. J., Hawkins, J. D., \& Abbott, R. D. (2004). Pathways from physical childhood abuse to partner violence in young adulthood. Violence and Victims, 19(2), 123-136.

Katz, J., Kuffel, S. W., \& Coblentz, A. (2002). Are there gender differences in sustaining dating violence? An examination of frequency, severity, and relationship satisfaction. Journal of Family Violence, 17(3), 247-271.

Kaufman, J., \& Zigler, E. (1987). Do abused children become abusive parents? The American Journal of Orthopsychiatry, 57(2), 186-192.

Lavoie, R, Hebert, M., Tremblay, R., Vitaro, F., Vézina, L., \& McDuff, P. (2002). History of family dysfunction and perpetration of dating violence by adolescent boys: A longitudinal study. The Journal of Adolescent Health, 30(5), 375-383.

Mihalic, S. W., \& Elliott, D. (1997). A social learning theory model of marital violence. Journal of Family Violence, 12(1), 21-47.

Muthén, L. K., \& Muthén, B. O. (1998-2007). Mplus: User's guide (5th ed.). Los Angeles, CA: Muthén \& Muthén.

Simons, R. L., Lin, K. H., \& Gordon, L. C. (1998). Socialization in the family of origin and male dating violence: A prospective study. Journal of Marriage and Family, 60(2), 467-478.

Spatz Widom, C. (1989). Does violence beget violence? A critical examination of the literature. Psychological Bulletin, 106(1), 3-28.

Stets, J. E., \& Straus, M. A. (1990). The marriage license as a hitting license: A comparison of assaults in dating, cohabiting, and married couples. In M. A. Straus \& R. J. Gelles (Eds.), Physical violence in American families: Risk factors and adaptations to violence in 8,145 families (pp. 227-244). New Brunswick, NJ: Transaction Publishers.

Stith, S. M., Rosen, K. H., Middleton, K. A., Busch, A. L., Lundeberg, K., \& Carlton, R. P. (2000). The intergenerational transmission of spouse abuse: A meta-analysis. Journal of Marriage and Family, 62(3), 640-654. 
Straus, M. A. (2004). Cross-cultural reliability and validity of the Revised Conflict Tactics Scales: A study of university student dating couples in 17 nations. Cross-Cultural Research, $38(4), 407^{\wedge} 32$.

Straus, M. A., Hamby, S. L., Boney-McCoy, S., \& Sugarman, D. B. (1996). The revised conflict tactics scales (CTS2): Development and preliminary psychometric data. Journal of Family Issues, 17(3), 283-316.

Swinford, S. P., DeMaris, A., Cernkovich, S. A., \& Giordano, P. C. (2000). Harsh physical discipline in childhood and violence in later romantic involvements: The mediating role of problem behaviors. Journal of Marriage and Family, 62(2), 508-519.

Tjaden, P., \& Thoennes, N. (2000a). Extent, nature, and consequences of intimate partner violence: Findings from the National Violence Against Women Survey. Washington, DC: National Institute of Justice.

Tjaden, P., \& Thoennes, N. (2000b). Prevalence and consequences of male-to-female and female-to-male intimate partner violence as measured by the National Violence Against Women Survey. Violence Against Women, 6(2), 142-161.

Wekerle, C., Leung, E., Wall, A. M., MacMillan, H., Boyle, M., Trocme, N., et al. (2009). The contribution of childhood emotional abuse to teen dating violence among child protective services-involved youth. Child Abuse \& Neglect, 33(1), 45-58.

Whitaker, D. J., Haileyesus, T., Swahn, M., \& Saltzman, L. S. (2007). Differences in frequency of violence and reported injury between relationships with reciprocal and nonreciprocal intimate partner violence. American Journal of Public Health, 97(5), 941-947.

Whitfield, C. L., Anda, R. R, Dube, S. R., \& Felitti, V. J. (2003). Violent childhood experiences and the risk of intimate partner violence in adults: Assessment in a large health maintenance organization. Journal of Interpersonal Violence, 18(2), 166-185.

Williams, S. L., \& Frieze, I. H. (2005). Patterns of violent relationships, psychological distress, and marital satisfaction in a national sample of men and women. Sex Roles, 52(11), 771-784.

Wolfe, D. A., \& Feiring, C. (2000). Dating violence through the lens of adolescent romantic relationships. Child Maltreatment, 5(4), 360-363.

Wolfe, D. A., Wekerle, C., Scott, K., Straatman, A. L., \& Grasley, C. (2004). Predicting abuse in adolescent dating relationships over 1 year: The role of child maltreatment and trauma. Journal of Abnormal Psychology, 113(3), 406-415.

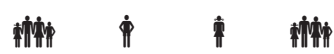

Acknowledgments - This research uses data from Add Health, a project directed by Kathleen Mullan Harris and designed by J. Richard Udry, Peter S. Bearman, and Kathleen Mullan Harris at the University of North Carolina at Chapel Hill, and funded by grant P01-HD31921 from the Eunice Kennedy Shriver National Institute of Child Health and Human Development, with cooperative funding from 23 other federal agencies and foundations. Special acknowledgment is due Ronald R. Rindfuss and Barbara Entwisle for assistance in the original design. Information on how to obtain the Add Health data files is available on the Add Health website - http://www.cpc.unc.edu/addhealth . No direct support was received from grant P01-HD31921 for this analysis.

Correspondence regarding this article should be directed to Kimberly A. Tyler, PhD, University of Nebraska-Lincoln, Department of Sociology, 717 Oldfather Hall, Lincoln, NE 68588-0324; email kim@ktresearch.net 